\title{
Article
}

\section{The impact of the Emergency Department target upon the discharge decision for people who self-harm}

\author{
Haslam, Michael and Jones, Emma \\ Available at http://clok.uclan.ac.uk/31896/ \\ Haslam, Michael ORCID: 0000-0002-9076-1481 and Jones, Emma ORCID: \\ 0000-0002-2153-2781 (2019) The impact of the Emergency Department \\ target upon the discharge decision for people who self-harm. Journal of Public \\ Mental Health, 19 (2). pp. 89-97. ISSN 1746-5729
}

It is advisable to refer to the publisher's version if you intend to cite from the work. http://dx.doi.org/10.1108/JPMH-01-2019-0003

For more information about UCLan's research in this area go to http://www.uclan.ac.uk/researchgroups/ and search for < name of research Group>.

For information about Research generally at UCLan please go to http://www.uclan.ac.uk/research/

All outputs in CLoK are protected by Intellectual Property Rights law, including Copyright law. Copyright, IPR and Moral Rights for the works on this site are retained by the individual authors and/or other copyright owners. Terms and conditions for use of this material are defined in the policies page.

\section{CLoK}

Central Lancashire online Knowledge www.clok.uclan.ac.uk

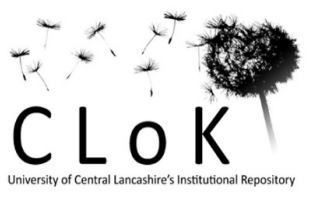


The impact of the Emergency Department target upon the discharge decision for people who self-harm

\begin{abstract}
Purpose: This study considers the influence of the Emergency Department (ED) target wait time upon the discharge decision in ED, specifically for patients who have self-harmed. Pressures to discharge patients to avoid breaching the four-hour target wait time, potentially increase the risk of adverse responses from clinicians. For the patient who has self-harmed, such interactions may be experienced as invalidating and may result in adverse outcomes.

Method: Secondary data analysis was applied to the retrospective referral data of a Mental Health Liaison Team (MHLT), collected over a period of 11 months from a single hospital in the North of England. In total, 734 episodes of care were referred to the team from ED, where the primary presentation was recorded as self-harm.
\end{abstract}

Findings: Over half of patients referred to the MHLT from ED having self-harmed were seen after already breaching the target and the potential for a more restrictive outcome reduced. Of those patients seen within four hours, the potential for a more restrictive treatment option was increased.

Social Implications: This study challenges the concept of the target as being realistic and attainable for patients who have self-harmed.

Practical Implications: Recommendations to improve the patient journey for those who have selfharmed include mental health triage and treatment in clinical areas outside of the target.

Originality/Value: This exploratory study provides a starting point from which to explore the impact of the target time upon discharge decisions and clinical outcomes specifically for those who have selfharmed.

\title{
Background
}

The four-hour target wait time was introduced at Emergency Departments (EDs) in the United Kingdom to reduce the time that patients attending ED, waited either to be admitted to a ward, transferred or discharged ( $\mathrm{DH}, 2001)$. Regarded as a simple measure of quality, the target is perceived to have improved the patient journey through the reduction in wait times for patients attending ED. Concerns, however, have been raised around the potential negative influence of the target upon workload and the quality of care delivered (Mortimore \& Cooper, 2007; Haslam, 2019). Additionally, performance against the target, currently set at $95 \%$, have fallen nationally, with only $77.2 \%$ of all attendances currently meeting the target (Nuffield Trust, 2019). Nationally, this performance dropped to its lowest at $75.7 \%$, in February 2019; the longest waits occurring in January and February due to an increase in respiratory illness and falls in the elderly and inpatient bed shortages.

For patients with mental ill health, the use of emergency care is over three times higher than the general population (Dorning, et al. 2015); self-harm ${ }^{1}$ being the most common psychiatric complaint (Mullins, et

${ }^{1}$ Self-harm is defined as "an act of self-poisoning or self-injury, irrespective of motivation" (NICE, 2013). 
al. 2010). A variable provision of community services for those who self-harm, means that patients seek to access support often through EDs, with self-harm already accounting for 150,000-170,000 of all ED attendances per year nationally (Aitkin, et al, 2014) and the numbers of young people self-harming rising (Tyrell et al, 2018). EDs therefore have an important role in the care of the individual who has self-harmed (HM Government, 2012).

For patients who self-harm, a time-commitment and good communication are said to be essential to allow collaborative relationships to emerge (HM Government, 2012; NCCMH, 2018). Attitudes, however, may already be negative towards those who self-harm, with staff members experiencing feelings of inadequacy and frustration when working with this patient group (Karman, et al. 2014). Exposures to intense emotion, repeat presentations and escalating behaviours evoke high levels of anxiety, helplessness and confusion in clinicians (Saunders et al. 2011; Conlon \& O'Tuathail, 2012; Rayner, et al. 2018) and discrepancies between the assessing clinician and the patient as to whether the ED visit is appropriate, may lead to invalidating responses from clinicians (Wise-Harris, et al. 2017).

Restrictions on time and communications; a potential risk of the four-hour target, may further compound this issue. Increasing pressures placed upon clinicians to avoid breaching the four-hour target may impact upon the quality of care delivered, reducing opportunities to develop a therapeutic alliance and increasing feelings of dismissal and rejection for the patient, particularly in the cases of those who do not feel ready to return home (Welch, 2010). Invalidating responses may potentially lead to volatility and non-compliance in patients and to adverse outcomes such as inadequate assessments of risk and avoidable hospitalizations (Mortimore \& Cooper, 2007; Shaikh, et al. 2017).

\section{Study Objectives}

Whilst the impact of non-clinical factors upon outcomes in ED, such as the four-hour target and ED census have been explored with other patient groups (Freeman, et al, 2009; Hoyle \& Grant, 2015; Pope, et al, 2017; Swancutt, et al, 2017), the four-hour target specifically upon discharge outcomes for those patients who have self-harmed does not appear to have been adequately explored. Previous research upon individuals presenting to ED with self-harm, has mainly considered the attitudes of clinicians and the management of the patient within the department (Betz \& Boudreaux, 2015; Steeg et al, 2017). This study is believed to be the first therefore to explore the impact of the four-hour target upon the discharge decisions for those patients who have self-harmed; exploring the potential relationship between the decision to discharge from ED, and whether the patient first breached the four-hour target.

\section{Method}

A quantitative approach was employed, analysing retrospective referral data to a Mental Health Liaison Team (MHLT). The MHLT conducts mental health and risk assessments to those of adult age who are presenting to, or having been admitted to, a general hospital and who are deemed to be experiencing significant distress or in crisis. MHLT's support acute hospital staff in making decisions around discharge planning and arranging follow up and future support around patients identified mental health 
needs (JCP-MH, 2012; Aitkin, 2007). This may be following episodes of self-harm. The MHLT from which the data was obtained, offers a 24-hour service, serving two hospitals, including two EDs and nearly 950 hospital inpatient beds. At the time that the data was collected, the team was based on site at the larger of the two hospitals and consisted of ten senior mental health nurses and four health care assistants.

\section{Sample}

This study used an opportunistic sample of mixed sex patients, aged 16 and over, who had presented to ED at a single hospital in the North of England, between January and November 2017. As this study focused upon 'episodes of care' there was a chance that patients attending multiple times within the period studied were included more than once, although attempts were made via the exclusion criteria to reduce the risk of re-enrolment of patients within the same episode of care, thus reducing the chance of reporting multiple outcomes per episode. Each episode of care was defined by the time period between the patient first presenting to ED and the time that the MHLT had completed their assessment (See fig. 1).

[Insert fig. 1 here]

\section{Data coding and analysis}

The referral data obtained had already been coded by the MHLT practitioners receiving the referral following triage in ED, according to the patients' primary presenting complaint. Those cases where it had not been made clear via the primary presenting complaint that the patient had self-harmed were excluded (table 1), leaving those identified to the MHLT with a primary presenting complaint of "Selfharm", "Suicide attempt" or with an "Overdose". In total, 734 episodes of care referred from ED to the team following self-harm, were eligible for inclusion in this study.

[Insert table 1 here]

Prior to analysis, the data was coded into two categories; those who, before the MHLT attended, had breached the four-hour target and those who did not. This was measured by the difference in the time between the person presenting to hospital and that the MHLT attended ED to review the patient.

The data was further divided into two groups; those cases which were discharged and those that were not. The patients discharged in this study were formally discharged by the MHLT following an assessment. Those patients who were not discharged, for the purposes of this study included those who were admitted directly to a psychiatric unit, referred for a mental health act assessment ${ }^{2}$ or referred to the Clinical Decisions Unit (CDU) ${ }^{3}$. Those patients transferred to a medical ward were excluded (table

\footnotetext{
${ }^{2} \mathrm{~A}$ mental health act assessment is a formal assessment under UK law to establish if a patient requires detention to a psychiatric inpatient unit for further assessment or treatment.

${ }^{3} \mathrm{~A} C D U$ is a short-stay unit where a patient with mental ill-health might be transferred for a further period of observation, assessment and support.
} 
1), to reduce the risk of patients being re-enrolled onto this study at a later point, during the same episode of care.

The data was then cross tabulated and descriptive statistics applied to establish any potential patterns. A Pearson's chi-squared test was employed to assess the significance of associations between the discharge decision and whether the patient first breached the four-hour target.

\section{Results}

Out of 734 care episodes, over a half of those referred to the MHLT from ED following self-harm (56.54\%), had already breached the four-hour target before being seen by the team (Table 2 ).

[Insert table 2 here]

Four fifths $(80.56 \%)$ of those patients seen by the team within four hours were discharged, but the percentage discharged, rose slightly when the patient was seen after breaching the target time. A chisquared test of independence was applied to the data, although the link between whether a person was discharged from ED and if they first breached the four-hour target was not significant at $X^{2}(1)=.091=$ $\mathrm{p}<.763$.

Overall, of those 734 episodes of care the percentages of direct inpatient admissions to psychiatric facilities from ED were consistent at just over 10\% regardless of whether the person was seen within or outside of the four-hour target. This figure is consistent with previous research for those who selfharmed (Parsonage, et al. 2012). Those seen by the MHLT within the first four-hours were more likely however to be referred for a mental health act assessment, than if they were seen after breaching the target, increasing their potential for inpatient admission. Conversely, there was an increase in the use of less restrictive options such as the clinical decisions unit for those seen after the four hours.

\section{Discussion}

Challenges upon ED achieving the four-hour target

For the location and time-period studied, over a half of those referred to the MHLT following self-harm, breached the four-hour target before being seen. As this figure was higher than the mean average for all conditions both for the ED in this study (25.6\%) and nationally (16\%) over the same 11-month period (NHS England, 2019), these findings reflect the significant challenges faced by EDs when treating patients who have self-harmed; indicating that four hours may be insufficient and not always attainable for this patient group. Longer stays for those who self-harm may be linked to the need to liaise with carers and external agencies (Bastiampillai, et al. 2012), as well as the patient's perceived level of risk and their need to be supported in times of crisis (Smith, et al. 2016). Furthermore, in the cases of those who have self-harmed, it may be unrealistic to complete investigations, to instigate treatment and to clear patients medically within four hours, particularly if a patient's condition is complicated by alcohol (Fee \& Weber, 2007). 
The impact of the target upon the discharge decision

The chances of being discharged from ED were increased if a patient was seen after the four-hour target time, as opposed to within the initial four-hours of presenting to ED. For those seen within four hours, more restrictive options were considered supporting the argument that that there is an increased potential for psychiatric admissions amongst those patients seen within four-hours. This is despite those cases being seen after breaching the four-hour target potentially being indicative of more complex or serious presentations requiring medical investigation and treatment.

An explanation for this association may be that the decision to admit a patient to hospital is appropriate for the patient's clinical presentation at the time of assessment. The way in which patients are prioritised may skew the data in favour of patients being seen earlier who are acutely unwell and require an inpatient admission whilst patients perceived to be a lower clinical priority, wait longer (Downing, et al. 2004). Additionally, informal triaging by MHLT Practitioners may influence the outcome; cases appearing more complex, being seen first whilst those appearing more straightforward being seen later. Longer waits in the department ensure that patients access interventions in the department that contribute to the resolution of their symptoms, thus allowing discharge to be considered.

Other explanations, however, might relate to the direct pressures placed upon the ED clinician by the target. When combined with the pressures of the four-hour target, staff ensuring a safe and therapeutic discharge for patients who self-harm, may offer patients an inpatient admission that might otherwise have been avoidable (Mortimore \& Cooper, 2007). Such admissions are likely to occur where there is a lack of access to previous patient notes, to ongoing support and where there is an impaired ability to obtain collateral information (Pope, et al. 2017) thus transferring such duties to the inpatient team outside of the target (Gorski, et al. 2016).

Avoidable admissions might also result from escalations in the patient's clinical presentation in response to perceived invalidating responses from clinicians. Negative attitudes from clinicians towards those who have attended previously, following self-harm, lead to tokenistic and task-focused care (Barnfield, et al. 2018). Compounded by a need to avoid a breach of the target, distorted responses from clinicians such as poor communication, have the potential to increase feelings of dismissal thus impacting upon the patient-clinician relationship (Wise-Harris, et al. 2017). For the distressed patient, such responses may lead to an escalation in distress and in risk-taking behaviours, leading to an admission that otherwise may have been avoidable, should they have received validating and supportive care.

\section{Implications for practice}

Regardless as to what extent the four-hour target influences discharge decisions, there remains a valid argument supporting the need for a different set of performance indicators for this patient group (Blunt, et al. 2015). Should the target remain in its present form following its review (NHS 2019), there is a valid argument for senior clinicians being granted the authority to breach the target for complex patient 
groups if needed (Hoyle \& Grant, 2015; Pope, et al. 2017). Such an approach would shift the focus from 'protocol-driven' to person-centred care (NCCMH, 2018). In terms of improving the patient ED journey, shorter term solutions may focus upon mental health triage and the use of specialist short-stay units.

Where, present guidance recommends that ED clinicians are capable in identifying mental ill health in those attending ED (NHS England, 2017), poor documentation of suicide risk factors and mental state, are considered to reflect the time pressures faced by staff (UI Haq, et al. 2010). Furthermore, delays to care and a lack of communication with patients in ED may instigate anxieties within patients (Swancut, et al. 2017) who are already likely to be experiencing a heightened state of emotion, potentially increasing feelings of invalidation and of being dismissed. A solution would be to integrate the hospital MHLT into the triage process, allowing the clinician to establish the person's capacity at the point of referral (Mullins, et al. 2010) and their needs whilst in ED (Steeg, et al. 2017). Mental health triage would promote an empathic, collaborative and patient-centred approach (NICE, 2013; Betz \& Boudreaux, 2015) through increasing staff awareness of patients' reasons for self-harm (Mullins, et al, 2010).

Triage is most effective where the MHLT have a permanent, integrated presence in ED, conducting parallel assessments (HSIB, 2018). This approach would contribute towards more positive beliefs towards this patient group (Rayner, et al. 2018) whilst allowing for crisis interventions to be applied (Shaikh, et al. 2017) and supporting management strategies of those patients who attend frequently and in the event of patients choosing to self-discharge before being seen (HSIB, 2018).

For those patients who do not require medical attention and have been declared medically fit, the use of specialist short stay units as places of safety might be employed as a way of supporting the patient who is distressed, outside of the four-hour target. Short stay units such as CDUs may lead to shorter hospital stays (Freeman, et al. 2010), allow a detailed assessment and brief interventions to take place in a less restrictive environment, whilst reducing those costs associated with inpatient admission (Bastiampillai, et al. 2012). If it is safe to wait there for a mental health assessment, patients might be taken there directly or deflected from ED at triage.

\section{Limitations}

Despite psychiatric inpatient admission rates being consistent with previous research (Parsonage, et al. 2012), the findings of this study are limited to describing the local clinical picture at the time that the data was obtained, and results should therefore be interpreted with care. The population served by the hospital from where this sample was obtained, experience higher levels of social deprivation (Department for Communities and Local Government, 2015) which is linked to an increase in ED use (Dorning, 2015). Young people from more poorer areas have double the incidence of poisonings compared to the least deprived areas (Tyrell, et al. 2018). Those from more deprived areas experience longer waits in ED compared to the general population due to the additional complexities of increased 
financial need, domestic violence, homelessness and alcohol and illicit substance misuse (Downing, et al. 2004).

Limitations of this paper are also related to the choice of secondary data analysis as the methodology. First, being heavily reliant upon the accuracy of the initial data recorded, there was no measure of consistency between the clinicians involved in the recording of this data. There was therefore an increased risk of valuable data being omitted through the exclusion criteria if self-harm was not recorded as the presenting complaint, potentially limiting the results. Second, whilst attempts were made via the exclusion criteria to reduce the potential for patients re-enrolling onto the study within the same episode of care, it was unknown from this data how many patients were repeat attendees and what potential impact this had upon the discharge decision. Furthermore, the data obtained was not powerful enough to establish the methods of, the severity of, or the intentions behind self-harm or to assess the appropriateness of the discharge decision.

Further research is needed to address the limitations around the study's generalizability and implications of the exclusion criteria. It may be that the target is unrealistic for all patient groups, not just those who self-harm. Prospective research studies might also explore the phenomenon of selfdischarge and might establish how repeat attendances and the differences in the type and severity of self-harm impact upon discharge decisions. Subsequent research might also use qualitative data to also explore the perceptions of patients around the value of the four-hour target. Nevertheless, in the absence of any other research directly relevant to this area, this method of investigation has allowed the impact of the target upon outcomes to be explored, without the manipulation of variables and more rigorous experimental methods that would be ethically challenging in ED.

\section{Conclusion}

Findings from this study challenge the notion that the four-hour target in ED is achievable particularly in the cases of those patients who have self-harmed. It may be that patients who self-harm are likely to breach the target due to complex social needs, increased risk and the need for medical clearance. Findings also indicate that for those who have self-harmed, there is an increased potential for admissions if seen within four-hours. Given that there is limited research that is of direct relevance to this area, this study provides a starting point from which to further explore the impact of the target upon discharge decisions, specifically for those who self-harm. Recommendations for practice include a mental health triage and safe areas to manage patients outside of the ED target.

\section{References}

Aitkin P. (2007) Mental Health Policy Implementation Guide: Liaison Psychiatry and psychological medicine in the General Hospital. Royal College of Psychiatrists. London.

Aitkin, P. Robens, S. \& Emmens, T. (2014) Model Service Specifications for Liaison Psychiatry Services - Guidance. $1^{\text {st }}$ edition. Strategic Clinical Network for Mental Health, Dementia and Neurological Conditions South West 
Barnfield, J., Cross, W. \& McCauley, K. (2018) Therapeutic optimism and attitudes among medical and surgical nurses towards attempted suicide. International Journal of mental health nursing. pp1827-1833

Bastiampillai, T., Schrader, G., Dhillon, R., Strobel, J. \& Bidargaddi, N. (2012) Impact of a Psychiatric unit's daily discharge rates on emergency department flow. Australasian Psychiatry, 20, 117120

Betz, M. E. \& Boudreaux (2015) Managing suicidal patients in the emergency Department. Annals of Emergency Medicine, 67, 276-282.

Blunt, I., Edwards, N. \& Merry, L. (2015) What's behind the A\&E 'crisis'? Policy Briefing \#3. Nuffield Trust.

Carroll, R., Corcoran, P., Griffin., E., Perry, I., Arensman, E., Gunnell, D. \& Metclafe, C. (2016) Variation between hospitals in inpatient admission practices for self-harm patients and its impact on repeat presentation. Social psychiatry, 51, 1485-1493

Clarke, D. E., Dunsome, D. \& Hughes, L. (2007) Emergency department from the mental health client's perspective. International Journal of Mental Health Nursing, 16, 126-131

Conlon, M. \& O'Tuathail, C. (2012) Measuring emergency department nurses' attitudes towards deliberate self-harm using the Self-Harm Antipathy Scale. International Emergency Nursing, $20,3-13$

Department for Communities and Local Government (2015) The English Indices of Deprivation 2015: statistical release. London.

Department of Health (2001) Reforming Emergency Care. DH. London.

Dorning (2015) Focus on: People with mental ill health and hospital use. Exploring disparities in hospital use for physical healthcare. Research summary. QualityWatch. The Health Foundation. Nuffield Trust.

Downing, A., Wilson, R. C. \& Cook, M. W. (2004) Which patients spend more than 4 hours in the Accident and Emergency department? Journal of Public Health, 26, 172-176.

Fee, C. \& Weber, E. (2007) Identification of $90 \%$ of patients ultimately diagnoses with communityacquired pneumonia within four hours of emergency department arrival may not be feasible. Annals of Emergency Medicine, 49, 553-559

Freeman, J. V., Croft, S., Cross, S., Yap, C. \& Mason, S. (2009) The Impact of the $4 \mathrm{~h}$ target on patient care and outcomes in the emergency department: an analysis of hospital incidence data. Emergency Medical Journal, 27, 921-927

Gorski, J. K., Batt, R. J., Otles, E., Shah, M.N., Hamedani, A. G. \& Patterson, B. W. (2016) The impact of Emergency Department Census on the Decision to admit. Academic Emergency Medicine, $24,13-21$

Haslam M (2019) How the emergency department four-hour target affects clinical outcomes for patients diagnosed with a personality disorder. Emergency Nurse. 27(4). pp20-24 
Healthcare Safety Investigation branch (2018) Investigation into the provision of mental health care to patients presenting at the emergency department. HSIB.

HM Government (2012) Preventing suicide in England: A cross-government outcomes strategy to save lives. London. HM Government.

Hoyle, L. \& Grant, A. (2015) Treatment targets in emergency departments: nurses' views of how they affect clinical practice. Journal of Clinical Nursing, 24

Joint Commissioning Panel for Mental Health (JCP-MH) (2012) Guidance for Commissioners of Liaison Mental Health Services to Acute Hospitals. Vol. 12. Practical Health Commissioning.

Karman, P., Kool, N., Poslawsky, I. E. \& Van Meijel, B. (2014) Nurses' attitudes towards self-harm: a literature review. Journal of Psychiatric and Mental Health Nursing, 22, 65-75

Lloyd-Rees, J. (2018) Supporting frequent attenders to reduce their vists to an emergency department. Emergency Nurse.

Mortimore, A. \& Cooper, S. (2007) The "4-hour target": Emergency nurse's views. Emergency Medical Journal online, 402-404.

Mullins, D., MacHale, S. \& Cotter, D. (2010) Compliance with NICE guidelines in the management of self-harm. The Psychiatrist, 385-389.

National Collaborating Centre for Mental Health (2018) Self-harm and Suicide Prevention Competence Framework: Adults and Older Adults. Commissioned by Health Education England. NCCMH

NHS (2019) Clinically-led Review of NHS Standards. Interim Report from the NHS National Medical Director.

NHS England (2019) A\&E attendances and emergency admissions. NHS England website. www.england.nhs.uk/statistics/statistical-work-areas/ae-waiting-times-and-activity/ (Accessed 08/2019)

NHS England (2016) Achieving Better Access to 24/7 Urgent and Emergency Mental Health CarePart 2: Implementing the evidence-based treatment pathway for urgent and emergency liaison mental health services for adults and older adults.

National Institute for Health and Care Excellence (2013) Self-harm: Quality Standard. NICE

Nuffield Trust (2019) A\&E waiting times. QualityWatch. Nuffield Trust \& The Health Foundation website. www.nuffieldtrust.org.uk/resource/a-e-waiting-times (Accessed 27/08/19)

Parsonage, M., Fossey, M. \& Tutty, C. (2012) Liaison Psychiatry in the Modern NHS. Centre for Mental Health, London.

Pope, I., Burn, H., Ismail, S. A., Harris, T. \& McCoy, D (2017) A qualitative study exploring the factors influencing admission to hospital from the emergency department. British Medical Journal Open, 7, 1-8

Rayner, G., Blackburn, J., Edward, K-L., Stephenson, J. \& Ousey, K. (2018) Emergency Department Nurses attitudes towards patients who self-harm: A meta-analysis. International Journal of Mental Health Nursing. pp1-14

Saunders, K., Hawton, K. \& Fortune S. (2011) Attitudes and knowledge of clinical staff regarding people who self-harm; systematic review. Journal of Affective Disorders, 139, 205-216. 
Shaikh, U., Qamar, I., Jafry, F., Hassan, M., Shagufta, S., Odhejo, Y. I. \& Ahmed, S. (2017) Patients with Borderline Personality Disorder in Emergency Departments. Frontiers in Psychiatry, 8, 112.

Smith, J. L., De Nadai, A. S., Storch, E. A., Langland-Orban, B., Pracht, E. \& Petrilla, J. (2016) Correlates of Length of Stay and Boarding in Florida Emergency Departments for Patients with Psychiatric Diagnoses. Psychiatric services, 67, 1169-1174

Steeg, S., Emsley, R., Carr, M., Cooper, J. \& Kapur, N. (2017) Routine hospital management of selfharm and risk of further self-harm: propensity score analysis using record-based cohort data. Psychological medicine, 1-12

Swancutt, D., Joel-Edgar, S., Allen, M., Thomas, D., Brant, H., Benger, J., Bying, R. \& Pinkney, J. (2017) Not all waits are equal: an exploratory investigation of emergency care patient pathways. $B M C$ health services research, 17, 1-10.

Tyrrell, E. G, Kendrick, D, Sayal, K.\& Orton, E. (2018) Poisoning substances taken by young people: a population-based cohort study. British Journal of General Practice. 8(675):e703-10.

UI Haq, S. U., Subramanyam, D. \& Agius, M. (2010) Assessment of self-harm in an accident and emergency service - the development of a proforma to assess suicide intent and mental state in those presenting to the emergency department with self-harm. Psychiatra Danunubina, 22, 26-32.

Welch, S. J. (2010) Twenty Years of patient satisfaction research applied to the emergency department: A qualitative review. American Journal of Medical Quality, 25, 64-72

Wise-Harris, D., Pauly, D., Kahan, D., Tan de Bibiana, J., Hwang, S. W. \& Stergiopoulos, V. (2016) "Hospital was the Only Option": Experiences of Frequent Emergency Department Users in Mental Health. Adm Policy Mental Health, 44, 405-412. 